\title{
Energy Efficiency of an Intermediate-temperature Solid Oxide Iron-Air \\ Redox Battery
}

\author{
Xinfang Jin ${ }^{1}$, Xuan Zhao ${ }^{1}$, Jingjing Tong ${ }^{1}$, Farzana Yasmeen ${ }^{1}$, Ralph E. White ${ }^{2}$ and Kevin \\ Huang $^{1 *}$ \\ ${ }^{1}$ Department of Mechanical Engineering, University of South Carolina, Columbia, SC29208, \\ USA \\ ${ }^{2}$ Department of Chemical Engineering, University of South Carolina, Columbia, SC29208, USA
}

\begin{abstract}
An ASPEN Plus based model is presented for an Intermediate-temperature Solid Oxide Iron-Air Redox Battery (IT-SOIARB) system. The model shows that the energy efficiency of the system can be as high as $83 \%$. Furthermore, the model is used to determine the factors that affect the energy efficiency of the battery. With air as the working fluid, a Heat Exchanger and Thermal Storage Unit are included in the battery system to utilize effectively the heat generated from the
\end{abstract}

\footnotetext{
*Corresponding author: huang46@cec.sc.edu
} 
discharge cycle in the charge cycle. The results show that air utilization (or air mass flow rate) plays a key role in regulating heat flow between the battery components.

KEYWORDS: battery; solid oxide fuel cell; air utilization; efficiency; heat balance

\section{Introduction}

Large-scale and cost-effective energy storage technology is vitally important to the implementation of a smart grid and renewable energy production. Among many types of energy storage options, Electrochemical Energy Storage (EES) technology is particularly attractive because of its fast response time, high energy capacity, modularity, and low cost. The major form of EES is rechargeable batteries, representative chemistries of which include the wellknown lead-acid ${ }^{1-3}, \mathrm{Ni}_{-} \mathrm{Cd}^{4,5}, \mathrm{Ni-} \mathrm{MH}^{6-8}, \mathrm{Li}^{-\mathrm{ion}^{9-11}}{ }^{\text {, redox flow }}{ }^{12-14}$ and Na-S ${ }^{15-17}$. For large-scale grid storage applications, only redox flow and $\mathrm{Na}-\mathrm{S}$ batteries have so far demonstrated the potential to be performance-competent and cost-effective. However, to be commercially viable, these technologies will need breakthroughs in materials discovery and engineering design.

In an effort to develop the next-generation advanced battery technology, we recently demonstrated a new type of battery based on reversible solid oxide fuel cells (RSOFCs) ${ }^{18-20}$. The core of the technology is the metal-air chemistry, storing and releasing oxygen in/by a metal/metal-oxide chemical bed integrated within a RSOFC operated under fuel-cell and electrolysis modes, respectively. Due to the use of solid oxide and redox materials, the new battery has also been named "Solid Oxide Metal-air Redox Battery" or SOMARB. Compared to other types of batteries, the new battery possesses many distinguishing advantages over conventional redox flow and Na-S batteries: higher energy density, faster charge/discharge rates, 
safety, environmental friendliness and scalability, and therefore promises to be a next-generation battery system for large-scale renewable and grid energy storage. Since its first laboratory demonstration in 2011, significant progress has been made in the areas of performance enhancement $^{21-29}$, new redox chemistries ${ }^{29-34}$ and computational analysis ${ }^{35-41}$. However, the ultimate commercialization of the SOMARB technology requires a full understanding of factors affecting system energy efficiency, which has not been addressed in the open literature.

In the present work, we present a system model to analyze the efficiency as well as performance determining factors for a Solid Oxide Iron-air Redox Battery or SOIARB operated at intermediate temperature, collectively IT-SOIARB. To increase the accuracy of the model, the electrochemical sub-model was validated by an experimental V-I curve. To achieve a heat balance between cycles, air was utilized as a working fluid to store, move and transfer heat among the three key components of the system: Heat Exchanger, Thermal Storage Unit (TSU) and IT-SOIARB Unit. The energy efficiency was particularly analyzed as a function of air utilization, current density and air outlet temperature.

\section{The IT-SOIARB system}

One of the most important thermal characteristics of the IT-SOIARB is the opposite heat signature for the discharge and charge cycles. An efficient utilization of the heat liberated from the discharge cycle $\left(\mathrm{H}_{2}\right.$ and iron oxidation reactions) by the endothermic charge cycle $\left(\mathrm{H}_{2} \mathrm{O}\right.$ and iron oxide reduction reactions) can lead to a better energy efficiency. In the present study, a separate air heat exchanger and thermal storage unit (TSU) are included as integrated parts of the system to reuse and capture the heat liberated from the discharge cycle for the charge cycle. Air 
is used as the working fluid to store, transport and transfer heat. Fig.1 shows a schematic of the IT-SOIARB system analyzed in this study. The operating temperatures of interest for the study are $550^{\circ} \mathrm{C}$ for the discharge cycle and $500^{\circ} \mathrm{C}$ for the charge cycle; at these temperatures the prevalent redox couple in the energy storage Redox Cycle Unit (RCU) is $\mathrm{Fe} / \mathrm{Fe}_{3} \mathrm{O}_{4}$. The operating temperature was assumed to be constant for simplicity.

(a) Discharge

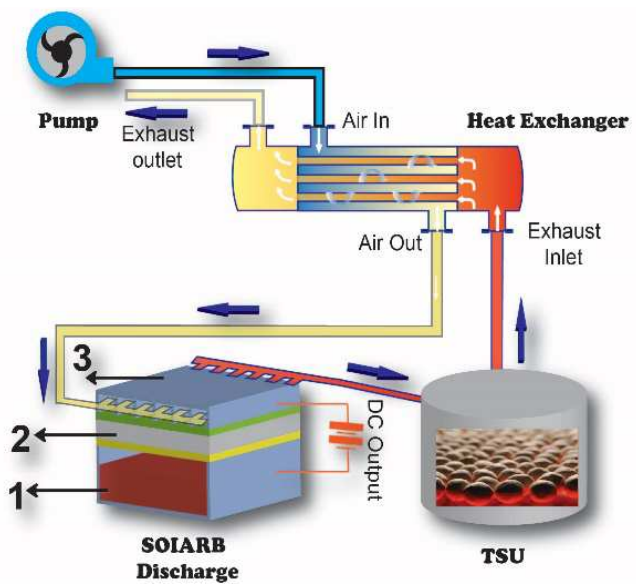

(b) Charge

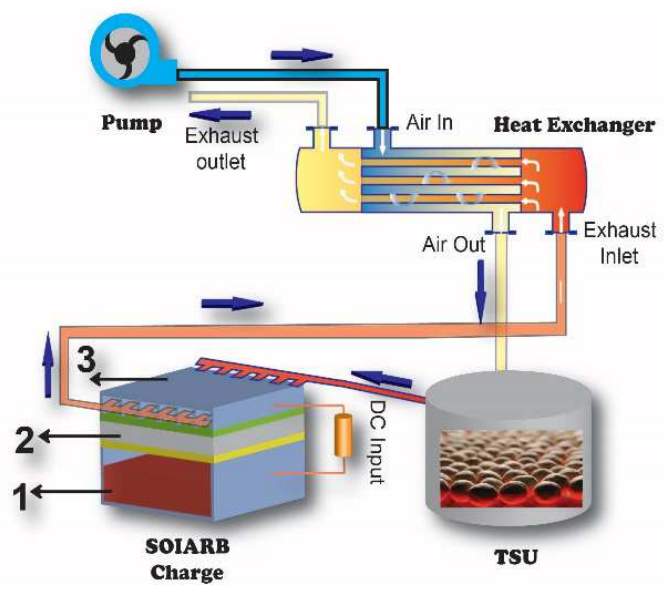

Fig. 1 A schematic of the analyzed IT-SOIARB system including the Thermal Storage Unit (TSU), (a) discharge cycle; (b) charge cycle. Nomenclature: 1-Redox Cycle Unit (RCU) containing $\mathrm{Fe} / \mathrm{Fe}_{3} \mathrm{O}_{4}$ chemical bed; 2-Reversible Solid Oxide Fuel Cell (RSOFC); 3-Air channel.

The system under analysis consists primarily of an IT-SOIARB stack, TSU, Heat Exchanger and Air Pump. During the discharge cycle, ambient fresh air is first preheated by the hot air exiting from the IT-SOIARB stack. This preheated air then enters the air channel of the IT-SOIARB. This design recovers the waste heat in the exhaust air while delivering $\mathrm{O}_{2}$ to the cathode for the electrochemical reaction. At the exit of the air channel, the heat-loaded air enters the TSU to store a majority of the process heat for the charge cycle. Clearly, the total molar flow rate of air, 
temperature of exhaust air and the capacity of the TSU will have a significant impact on the thermal balance and therefore the energy efficiency of the system. For the charge cycle, the above process flows are reversed as shown in Fig.1 (b). In this case, the preheated air passes through the TSU to extract stored heat before entering the IT-SOIARB stack.

\section{Model description}

A 5kW/60kWh IT-SOIARB system intended for residential solar panel/battery applications was modeled by using the commercial software known as ASPEN Plus ${ }^{42}$. The simulation flow diagram for the system shown in Fig.1 is illustrated in Fig.2, which contains all the components and functionalities specified in the IT-SOIARB system.

(a) Discharge

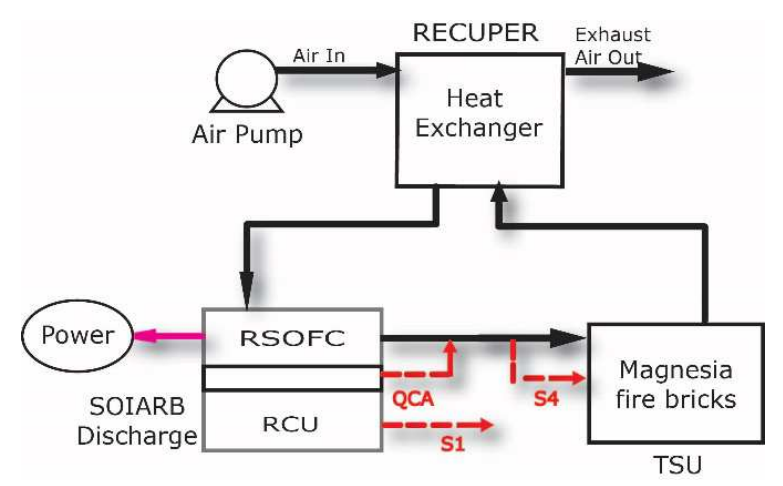

(b) Charge

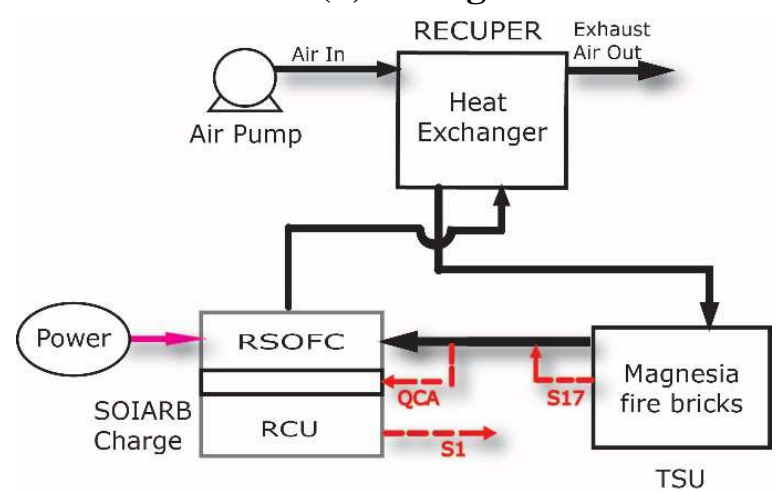

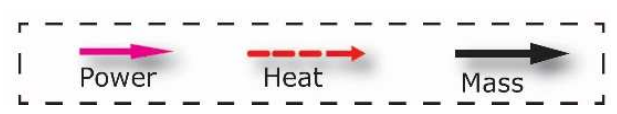

Fig. 2 Process diagram of an IT-SOIARB system: (a) Discharge cycle; (b) Charge cycle. RSOFC: Regenerative Solid Oxide Fuel Cell; RCU: Redox Couple Unit, here is $\mathrm{Fe}_{-} \mathrm{Fe}_{3} \mathrm{O}_{4}$; TSU: Thermal Storage Unit. 
In Fig.2, the mass and heat streams are represented by black solid lines and red dashed lines, respectively, while the power input/output streams are represented by magenta solid lines. The heat streams S1 accounts for the heat leakage of the battery during cycles, S4 for the heat stored in TSU during the discharge cycle, S17 for the heat supplied by TSU for the charge cycle, and finally QCA for the heat demand by the charge cycle, or heat released by the discharge cycle. The power terms PA represent the power output from the discharge cycle and input for the charge cycle, respectively.

The commercial system software known as Aspen Plus was selected for the analysis. This software is capable of calculating thermodynamic properties at a defined states of chemical processes. Details of the model construction can be found in the Appendix. The general considerations/assumptions used in the model are:

1. Air is composed of $\mathrm{O}_{2}, \mathrm{~N}_{2}$ and $\mathrm{H}_{2} \mathrm{O}$, with a composition (mole fraction) of 0.21:0.78:0.01.

2. The reaction occurring in SOIARB is simplified to the overall reaction, as there is no built-in module for the battery in ASPEN Plus.

3. No degradation is considered for the RSOFC or RCU bed, which enables us to treat dynamic discharge/charge as a steady-state process.

4. All the components operate under isothermal and isobaric conditions.

5. The power input/output is calculated by a FORTRAN block, and executed within ASPEN Plus.

6. Heat exchanger and Thermal Storage Unit are represented by a built-in heat exchanger blocks in ASPEN Plus. 


\subsection{The Chemical and Electrochemical reactions in SOIARB}

The reactions occurring in the RSOFC and the RCU can be expressed as follows ${ }^{38}$ :

$$
\begin{aligned}
& \mathrm{O}_{2} \text {-electrode of RSOFC: } \frac{1}{2} \mathrm{O}_{2}(g)+2 e^{-} \frac{\text { discharge }}{\overline{\text { charge }}} \mathrm{O}^{2-} \\
& \mathrm{H}_{2} \text {-electrode of RSOFC: } \mathrm{H}_{2}(g)+\mathrm{O}^{2-} \frac{\text { discharge }}{\text { charge }} \mathrm{H}_{2} \mathrm{O}(g)+2 e^{-} \\
& \text {RCU: } 4 \mathrm{H}_{2} \mathrm{O}(\mathrm{g})+3 \mathrm{Fe}(s) \stackrel{\text { discharge }}{\text { charge }} \mathrm{Fe}_{3} \mathrm{O}_{4}(s)+4 \mathrm{H}_{2}(g)
\end{aligned}
$$

Since all of the reactions occur in the same reactor, the following overall battery reaction, which is a summation of eq. (3-1) to (3-2) can be written as:

$$
3 \mathrm{Fe}(s)+2 \mathrm{O}_{2}(g) \leftrightarrows \mathrm{Fe}_{3} \mathrm{O}_{4}(s)
$$

\subsection{Electrochemical sub-model for SOIARB}

The cell voltage is critical in determining the heat associated with polarization during the discharge and charge cycles. It is a common practice in the open literature to first validate electrochemical parameters with experimental data, followed by predicting voltage at other

operating conditions ${ }^{43,44}$. In this model, we applied a Calculator Fortran block function to extract electrochemical parameters from an experimental V-I curve obtained for the RSOFC.

\subsubsection{Equations for overpotentials}

The stack voltage is determined by:

$$
V=O C V \mp\left(\eta_{a c t, a n}+\eta_{a c t, c a t}+\eta_{\text {ohm }}+\eta_{c o n, a n}+\eta_{c o n, c a t}\right)
$$


where OCV is the open circuit voltage; $\eta_{\text {act }}, \eta_{\text {ohm }}$ and $\eta_{\text {con }}$ represent the voltage losses due to activation, ohmic and concentration polarizations, respectively. The subscript "an" and "cat" represent Anode and Cathode, respectively. The "_" sign is for the discharge cycle, and the "+" sign is for the charge cycle.

The OCV of the battery is defined by the Nernst equation for reactions (3-1) and (3-2):

$$
\mathrm{OCV}=-\frac{\Delta G^{0}}{2 F}-\frac{R T}{2 F} \ln \left(\frac{p_{\mathrm{H}_{2} \mathrm{O}, h}}{p_{O_{2, o}}^{0.5} p_{\mathrm{H}_{2, h}}}\right)
$$

where $p_{O_{2, o}}, p_{H_{2, h}}$ and $p_{H_{2} O, h}$ represent the partial pressures of $\mathrm{O}_{2}, \mathrm{H}_{2}$ and $\mathrm{H}_{2} \mathrm{O}$, in oxygen or hydrogen electrode respectively; $\Delta G^{0}$ is the change of the standard Gibbs free energy between the products and the reactants. For example, under the operating condition of $\mathrm{T}=823.15 \mathrm{~K}$, $\Delta G^{0}=-202.345 \mathrm{~kJ}, p_{O_{2, o}}=0.21 \mathrm{~atm}, \quad p_{H_{2, h}}=0.79 \mathrm{~atm}, \quad p_{H_{2} O, h}=0.21 \mathrm{~atm}$, resulting in a $\mathrm{OCV}=1.068 \mathrm{~V}$

The activation polarization, $\eta_{\text {act,an/cat }}$, can be determined by the Butler-Volmer equation ${ }^{45}$ :

$$
J_{i c t, a n / c a t}=2 J_{0, a n / c a t} \sinh \left(\frac{n F}{2 R T} \eta_{a c t, a n / c a t}\right)
$$

Here $J_{0, a n / c a t}$ and $J_{i c t, a n / c a t}$ are the exchange and local charge transfer current densities in the Anode or the Cathode, respectively $\left(\mathrm{A} \cdot \mathrm{m}^{-2}\right) ; \mathrm{n}$ is the number of electrons transferred, $(\mathrm{n}=1) ; F$ is the Faraday constant $96485\left(\mathrm{C} \cdot \mathrm{mol}^{-1}\right) ; R$ is the gas constant $8.314\left(J \diamond\left(\mathrm{mol}^{-1} \diamond K^{-1}\right)\right)$.

The ohmic loss $\eta_{\text {ohm }}$ results mainly from the ionic resistance of the electrolyte: 


$$
\eta_{\text {ohm }}=\frac{1}{\sigma_{i, \text { ele }}} \times \delta_{\text {ele }} \times J
$$

Here, $\sigma_{i, e l e}\left(\mathrm{~S} \cdot \mathrm{m}^{-1}\right)$ and $\delta_{\text {ele }}(\mu \mathrm{m})$ are the ionic conductivity and thickness of the dense electrolyte, respectively, and $\mathrm{J}$ is the operating current density, $\left(\mathrm{A} \cdot \mathrm{m}^{-2}\right)$.

The concentration overpotential $\eta_{\text {con,an/cat }}$ is governed by:

$$
\eta_{\text {con }, \text { an } / c a t}=\frac{R T}{n F} \ln \left(1-\frac{J}{J_{L, a n / c a t}}\right)
$$

where $J$ and $J_{L, \text { an/cat }}$ are the operating current density and limiting current density, respectively. The limiting current density $\mathrm{J}_{\mathrm{L}, \mathrm{an} / \mathrm{cat}}$ is calculated by:

$$
J_{L, a n / c a t}=\frac{2 F \diamond p_{i} \diamond D_{e f f, m n}}{R T \delta_{e, a n / c a t}}
$$

where $D_{e f f, m n}=D_{m n} \frac{\varepsilon}{\tau}$ is the effective diffusivity of species $\mathrm{m}$ in a gas mixture $\mathrm{m}-\mathrm{n} ; D_{m n}$ is the ordinary diffusivity of species $\mathrm{m}$ in a gas mixture $\mathrm{m}-\mathrm{n} ; \varepsilon$ and $\tau$ are the porosity and tortuosity of the electrodes, respectively; $\mathrm{p}_{\mathrm{i}}$ is the partial pressure of reactant species; $\delta_{e, \text { an } / c a t}$ is the thickness of anode/cathode electrode.

\subsubsection{Validation of Electrochemical sub-model}

The electrochemical sub-model including a FORTRAN block for calculating power output and input was developed based on experimental data. To do so, the electrochemical parameters of RSOFC were firstly extracted from an experimental V-I curve (see Fig.3, red circles) obtained 
from a button cell in our lab ${ }^{46,47}$. All the parameters obtained are listed in Table 1. Excellent agreement between the model predications and the experimental data is shown in Fig.3.

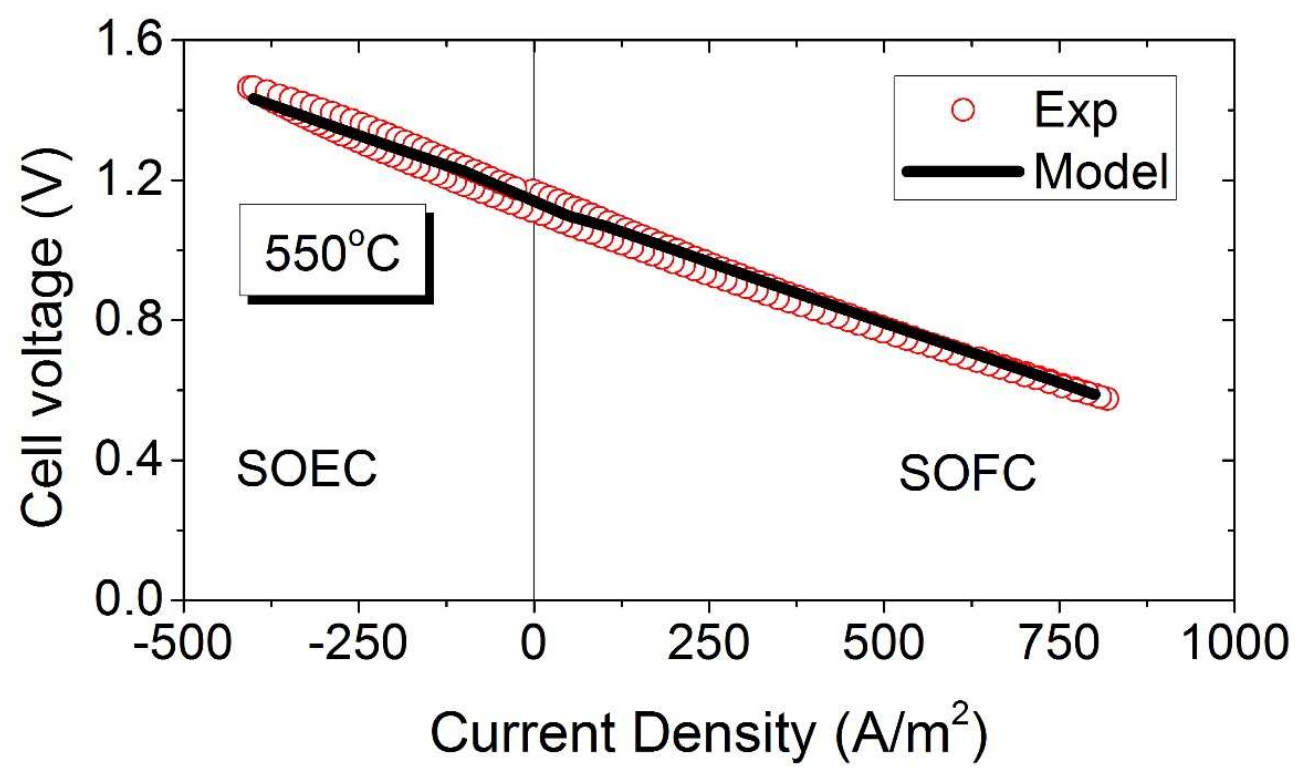

Fig. 3 Model validation by experimental data (SOEC: Solid Oxide Electrolysis Cell; SOFC:

Solid Oxide Fuel Cell.)

Note: The parameters with $*$ are adjusted in order to validate the model with the experimental results.

\subsection{Efficiency of the system}

The air pumping power is given by:

$$
P_{\text {pump }}=\frac{\Delta p V_{m} F_{\text {air }}}{\eta_{\text {pump }}}
$$


Here, $\Delta p$ is the pressure drop through the whole system; $\eta_{\text {pump }}$ is the pump efficiency; $\mathrm{V}_{\mathrm{m}}$ is the molar volume of air, $\left(\mathrm{m}^{3} \cdot \mathrm{mol}^{-1}\right) ; \mathrm{F}_{\text {air }}$ is molar flow rate of air, $\left(\mathrm{mol} \cdot \mathrm{s}^{-1}\right)$.

The system energy efficiency $\left(\eta_{\text {energy }}\right)$, which accounts for the electrical energy generated from the discharge cycle, supplied to the charge cycle and pumping air is given by:

$$
\eta_{\text {energy }}=\frac{E_{d}}{E_{c}+P_{\text {pump }} \times h_{\text {cycle }}+\text { Heat }}
$$

where $h_{c y c l e}$ is the cycle time in hours; Heat $=H_{e a t} t_{S 17}-H_{e a t}$ is the external heat needed to maintain the charge cycle at isothermal conditions. Ideally, Heat $=0$.

\subsection{Air outlet temperature}

The air outlet temperature for the discharge cycle is obtained by optimizing the Design-Spec block diagram loop shown in Fig.4 while meeting the desired power output "PA" as a criterion:

$$
P A=V \times J \times A
$$

Here $\mathrm{V}$ is the cell voltage, $(\mathrm{V})$; $\mathrm{J}$ is the operating current density, $\left(\mathrm{A} \cdot \mathrm{m}^{-2}\right)$; $\mathrm{A}$ is the cross-sectional area of the battery, $\left(\mathrm{m}^{2}\right)$. 


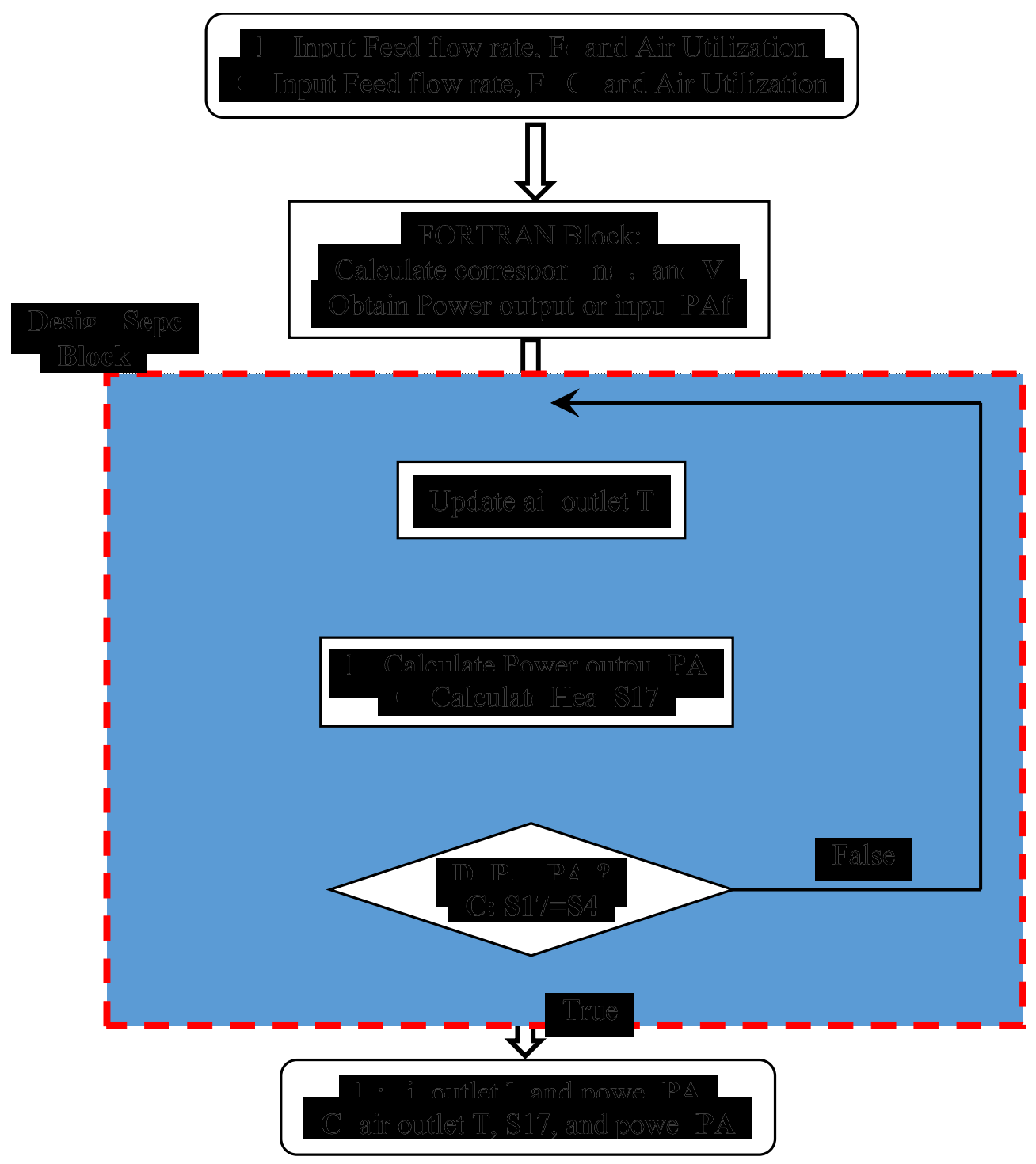

Fig.4 Optimization block diagram to obtain air outlet temperature (D: discharge; C: charge)

For the charge cycle, the air outlet temperature is adjusted within the Design-Spec block to ensure all the heat stored in TSU during the discharge cycle is fully extracted for the charge cycle:

$$
\text { Heat }_{S 17}-\text { Heat }_{S 4}=0
$$


If this heat is insufficient, the computation will not converge, which means external heat will be needed by the amount of Heat $=$ Heat $_{S 17}-$ Heat $_{S 4}$.

The air utilization ratio $R_{\text {air }}$ is an important engineering parameter for operating an efficient ITSOIARB. The air utilization ratio is related to the air flow rate $F_{\text {air }}$ as follows:

$$
R_{\text {air }}=\frac{F_{\mathrm{O}_{2}} / 0.21}{F_{\text {air }}}=\frac{\frac{2}{3} F_{\mathrm{Fe}} / 0.21}{F_{\text {air }}} \operatorname{or} \frac{2 F_{\mathrm{Fe}_{3} \mathrm{O}_{4}} / 0,21}{F_{\text {air }}}
$$

where, $F_{\mathrm{O}_{2}}, F_{\text {air }}, F_{\mathrm{Fe}}$ and $F_{\mathrm{Fe}_{3} \mathrm{O}_{4}}$ are the molar flow rates of $\mathrm{O}_{2}$, air, $\mathrm{Fe}$ and $\mathrm{Fe}_{3} \mathrm{O}_{4}$ streams respectively.

\section{Results and discussion}

The Energy output/input (kWh) vs theoretical values under different current densities of an ITSOIARB during the discharge/charge cycle calculated on the basis of the V-I curve shown in Fig.3 are depicted in Fig.5 as a function of J, where $E_{d}$ or $E_{c}=t \times V \times J \times A$; t is the cycle time, V is cell voltage at $\mathrm{J}$, and $\mathrm{A}$ is the effective area of the IT-SOIARB. Because of the polarization losses, the energy output during the discharge cycle $\left(\mathrm{E}_{\mathrm{d}}\right)$ is lower than the theoretical Gibbs free energy change of the reaction $(\Delta \mathrm{G}): \mathrm{H}_{2}(g)+0.5 \mathrm{O}_{2}(g)=\mathrm{H}_{2} \mathrm{O}(g)$. The energy input during the charge cycle $\left(\mathrm{E}_{\mathrm{c}}\right)$ is higher than the theoretical $\Delta \mathrm{G}$. When $\mathrm{E}_{\mathrm{c}}=\Delta \mathrm{H}$ (the enthalpy change of the overall reaction $\left.0.75 \mathrm{Fe}+0.5 \mathrm{O}_{2}(g)=0.25 \mathrm{Fe}_{3} \mathrm{O}_{4}\right)$, the battery becomes thermally neutral. From Fig.5, it is evident that the higher the charging current density (more negative), the less heat 
needed $\left(\mathrm{E}_{\mathrm{c}}-\Delta \mathrm{H}\right)$ for the charge cycle. No heat is needed for the charge cycle when the operating current density is more negative than $-300 \mathrm{~A} / \mathrm{m}^{2}$, however, the overall efficiency is lower.

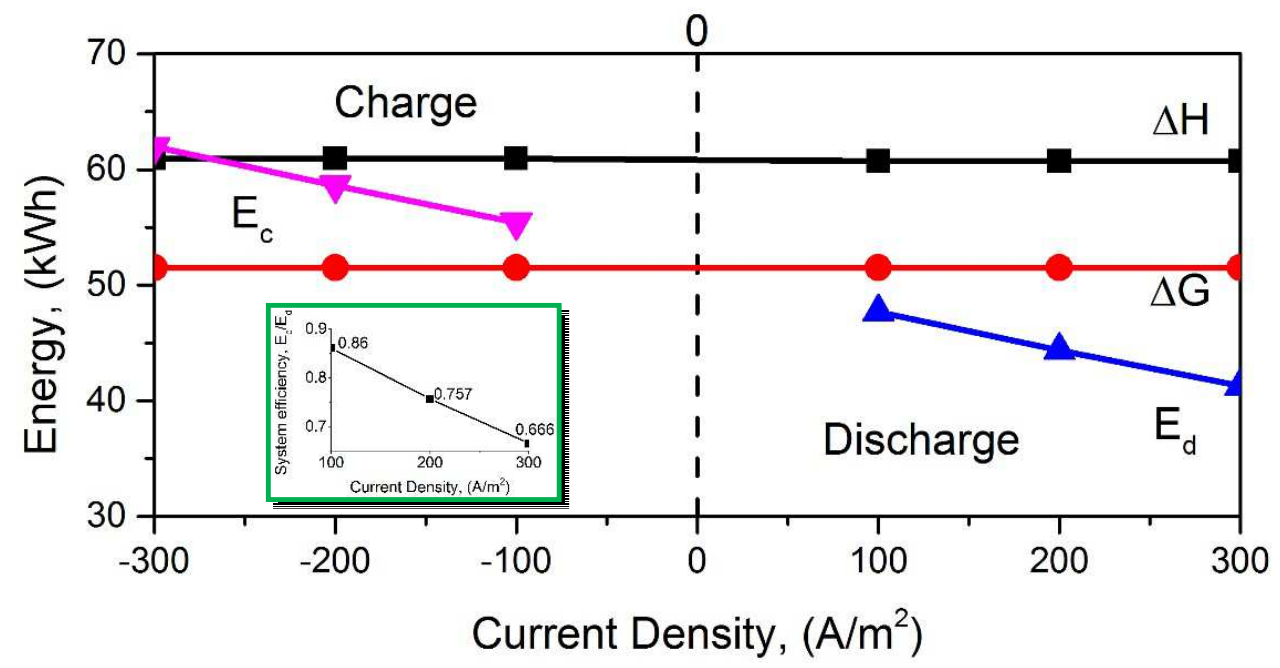

Fig. 5 Energy output/input (kWh) vs theoretical values under different current densities.

To maintain a high efficiency, the operating current density should be as small as possible. On the other hand, to satisfy the heat demand of a charge cycle by reusing heat from a discharge cycle, the operating current density should be relatively large. For a given energy capacity, e.g. $60 \mathrm{kWh}$ for the present study, the cycle time is inversely proportional to the current density. To study the effect of the operating current density on heat balance and energy efficiency, the following three cases are examined:

Case-1: at $\mathrm{J}=100 \mathrm{~A} / \mathrm{m}^{2}$ for $h_{\text {cycle }}=12$ hours for both discharge and charge cycle

Case-2: at $\mathrm{J}=150 \mathrm{~A} / \mathrm{m}^{2}$ for $h_{\text {cycle }}=8$ hours for both discharge and charge cycle

Case-3: at $\mathrm{J}=200 \mathrm{~A} / \mathrm{m}^{2}$ for $h_{\text {cycle }}=6$ hours for both discharge and charge cycle

\subsection{Heat stored $v s$ recovered in TSU}


As shown in Fig.2, the heat stored in the TSU from a discharge cycle is represented by S4, while the heat recovered from TSU for a charge cycle is S17. The actual heat demand from the charge cycle, QCA, is the heat absorbed by the battery, the difference of which from S17 is the irreversible heat loss. These heat-related quantities are investigated as functions of air utilization and operating current densities. The optimal air utilization would occur when S4 = S17.

Fig. 6 shows S4, S17 and QCA as a function of air utilization for Case-1. It is evident that the actual heat demand for the charge cycle, $\mathrm{QCA}=5.45 \mathrm{kWh}$, is only a function of operating current density and independent of air utilization. The heat demand is met by two heat sources: (1) the heat stored in TSU; (2) the heat stored in $\mathrm{O}_{2}$ product from the battery. The first heat source is the major contributor to the heat supply for the charge cycle. As evident in Fig.6, the heat S17 needed from TSU (Hollow Square) is more than S4 stored in TSU (Solid Square). To meet the heat demand, the heat in the air must be recuperated. In order to balance the heat between the cycles, air utilization must be operated at less than $8 \%$. Since the second heat source is relatively small and plays an insignificant role in the overall heat supply, the heat demand by the charge cycle S17 can be easily fulfilled when the heat stored by the discharge cycle S4 reaches $5 \mathrm{kWh}$.

For air utilization $>10 \%, \mathrm{~S} 17$ of the charge cycle is a constant; this results from a combined effect of air utilization and air outlet temperature. Under such a case, external heat is needed in order to converge the model. 


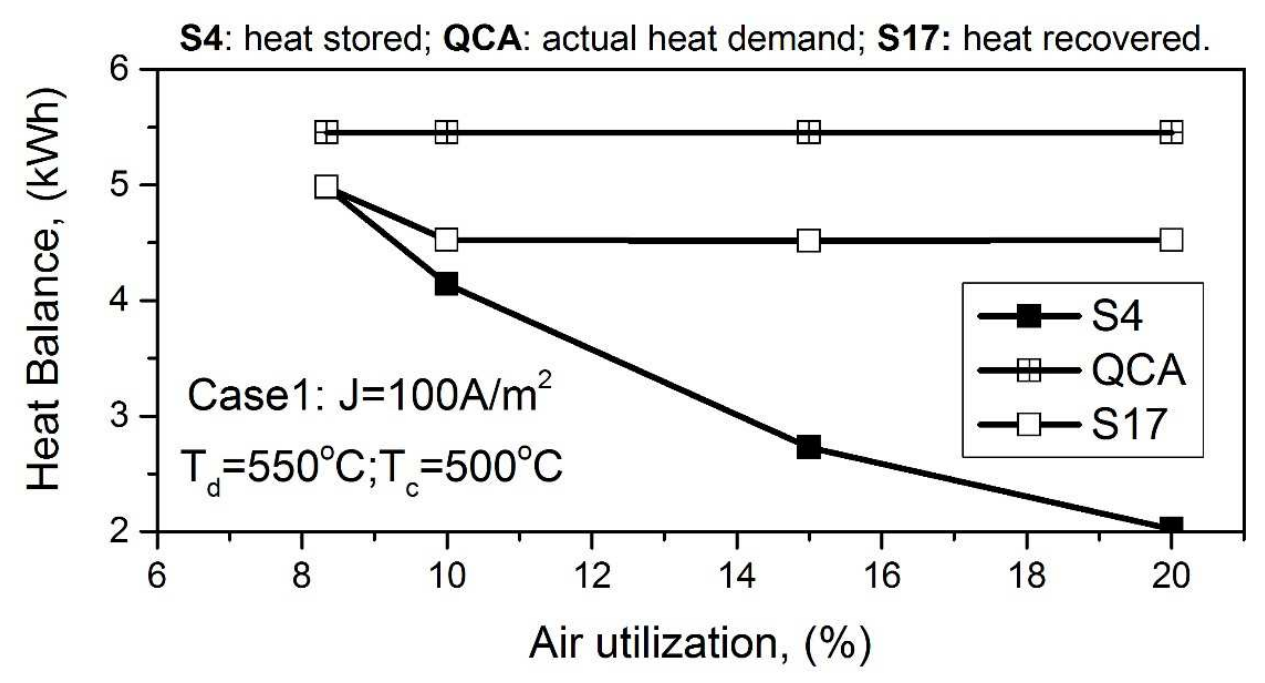

Fig. 6 Heat balance $v s$ air utilization for Case-1

At a higher current density $150 \mathrm{~A} / \mathrm{m}^{2}$, Case-2, Fig. 7 illustrates that the actual heat demand QCA is reduced to $3.92 \mathrm{kWh}$, representing a $28 \%$ decrease. As a result, the heat $\mathrm{S} 4$ stored in TSU (Solid Circle) converges with the heat S17 needed from TSU (Hollow Circle) at a higher air utilization $\sim 13 \%$. In other words, to achieve the heat balance without external heat input, air utilization must be $<13 \%$. Operating with an air utilization above $13 \%$ would result in unnecessary heat loss due to exhausting hotter air, lowering overall energy efficiency.

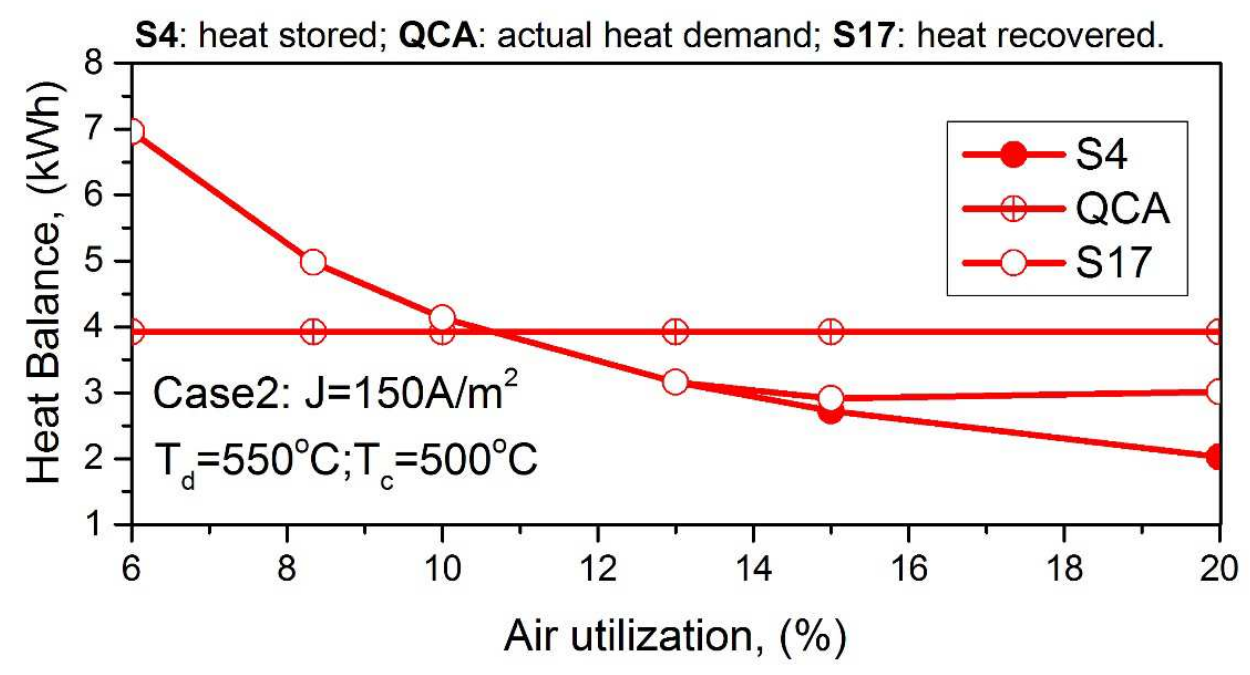


Fig. 7 Heat balance $v s$ air utilization for Case-2

At an even higher current density of $200 \mathrm{~A} / \mathrm{m}^{2}$, Case-3, Fig. 8 shows a further lowering of the heat demand $\mathrm{QCA}=2.22 \mathrm{kWh}$. Operating at as high as $15 \%$ air utilization can meet the heat requirement. At an operating current density $>200 \mathrm{~A} / \mathrm{m}^{2}$, QCA would no longer be needed. However, the compromise is the much lower cycle efficiency.

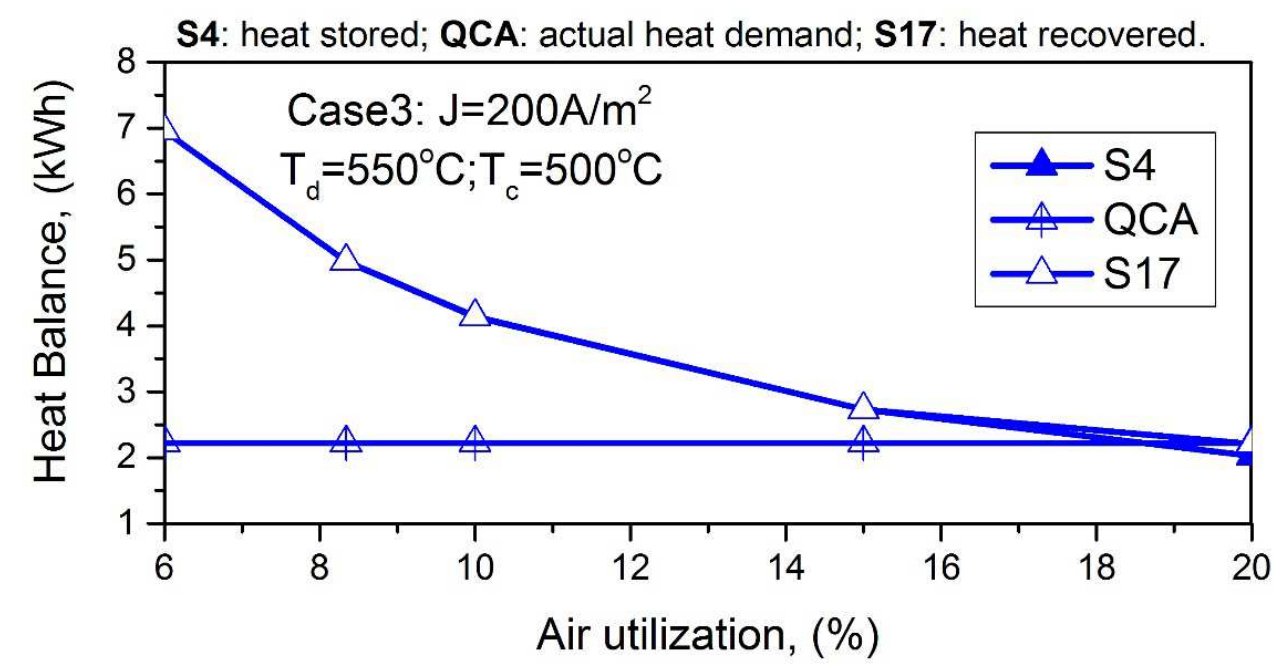

Fig. 8 Heat balance $v s$ air utilization for Case-3

\subsection{Air Outlet Temperature}

\subsubsection{Discharge cycle}

As aforementioned, air outlet temperature can be an indicator of how well the heat is balanced within the system. It can be determined by optimizing the Design-Spec block to meet the energy output PA requirement as described in section 3.4. The actual air outlet temperature reflects the degree of the unutilized heat by the system. 
The air outlet temperatures under the three Cases are plotted in Fig.9 as a function of air utilization for the discharge cycle. The total heat balance of the system can be calculated by:

$\vartheta H=t\left(P A+S 1+S 4+\left(C_{p} \times M_{\text {air }} \times F_{\text {air }, \text { out }} \times T_{\text {air }, \text { out }}-C_{p} \times M_{\text {air }} \times F_{\text {air, in }} \times T_{\text {air }, \text { in }}\right)\right)$

where PA and S1 are determined by Fe molar flow, and independent on air utilization. It is evident that increasing air utilization elevates $T_{\text {air,out }}$. This is because $\mathrm{F}_{\text {air }}$ and $\mathrm{S} 4$ is decreased by increasing air utilization. For all the cases, the higher the operating current density the higher the $T_{\text {air }, \text { out }}$. Note that the heat in the air exhaust was not counted in eq. (3-12) for the energy efficiency calculation. If this part of the waste heat can be utilized, especially at higher operating current density, the overall system efficiency can be further improved.

The selection of $\Delta \mathrm{T}=50^{\circ} \mathrm{C}$ between charge and discharge is based on the consideration whether the induced thermal stress can be acceptable by the industry standard. Lower $\Delta \mathrm{T}$ would certainly be preferable to minimize the stress, but increase the demand for higher air flow. The latter would result in a higher pressure drop and parasitic power loss. 


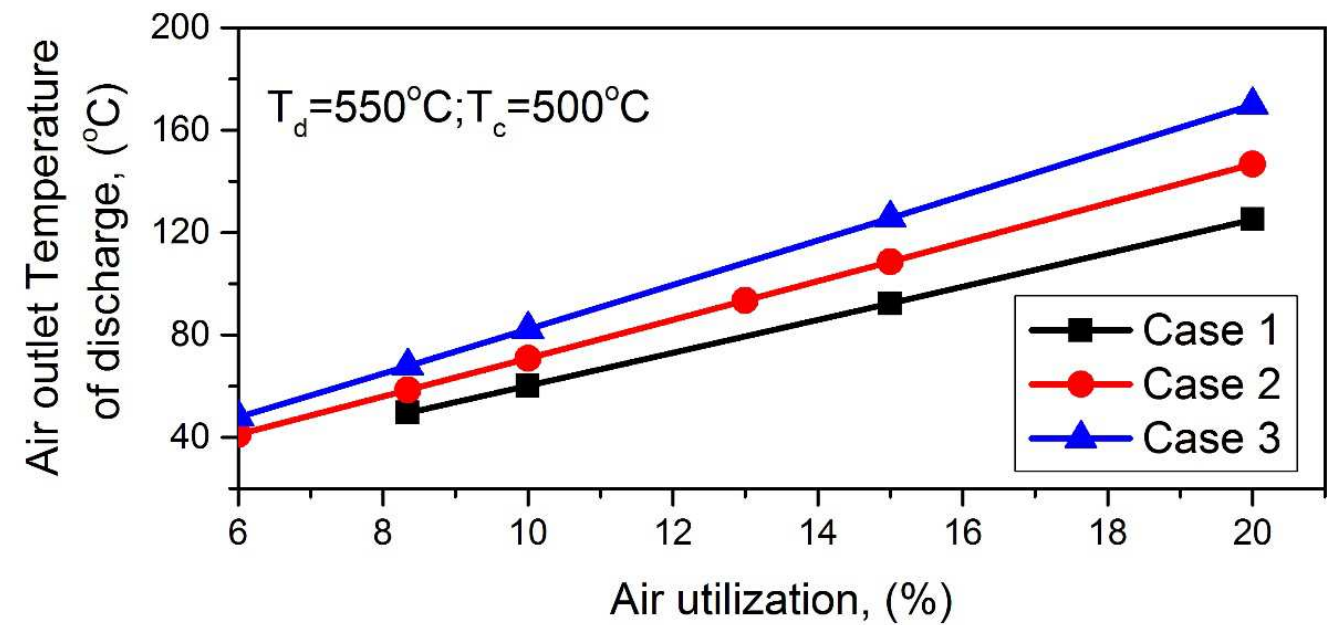

Fig. 9 Air utilization vs air outlet temperature during the discharge cycle for the three cases studied

\subsubsection{Charge cycle}

For the charge cycle, the heat stored in the TSU through the discharge cycle is assumed to be $100 \%$ reused by the charge cycle. The air outlet temperature is allowed to vary with current density. Fig.10 shows the results for the three cases. For Case-1, external heat is needed to provide sufficient heat for the charge cycle if the air utilization is over $8 \%$. Under such a circumstance, the air outlet temperature varies within $\sim 40-50^{\circ} \mathrm{C}$. For Case- 2 , it is $>13 \%$ for air utilization when external heat is needed. The air outlet temperature varies within $\sim 45-50^{\circ} \mathrm{C}$. For Case-3, no external heat is needed for air utilization ranging from 6 to $20 \%$, yielding air outlet temperature within $\sim 55-60^{\circ} \mathrm{C}$. 


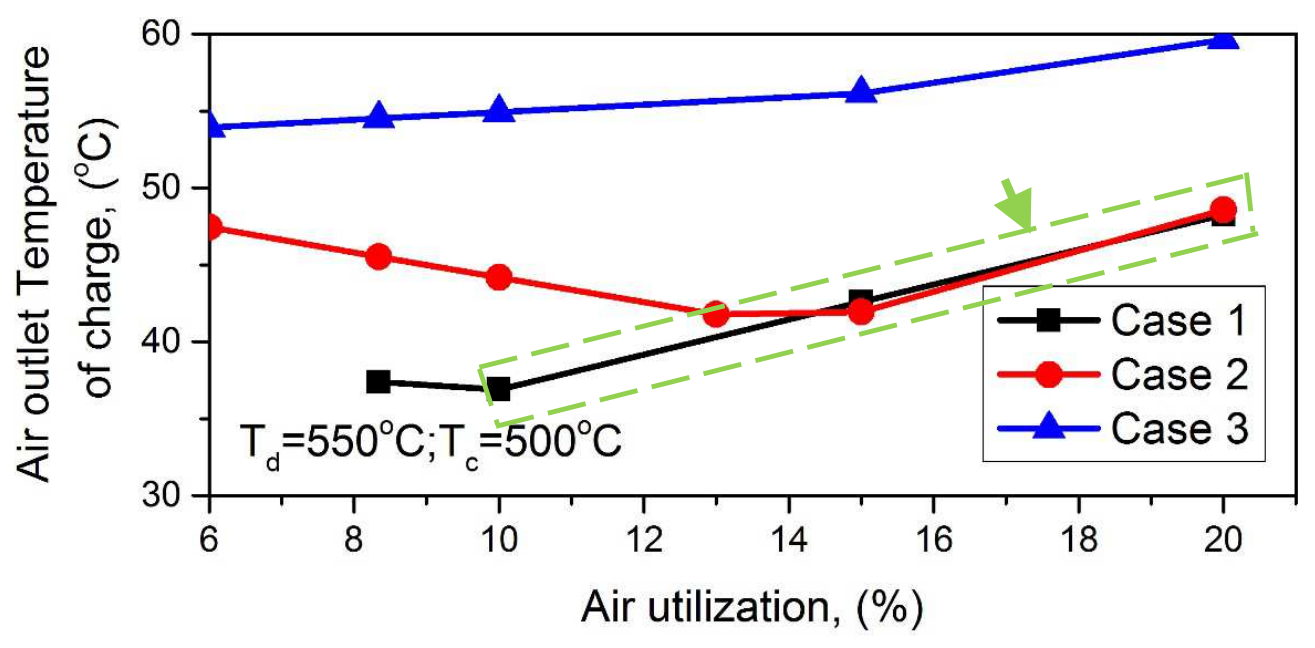

Fig. 10 Air utilization $v s$ air outlet temperature during the charge cycle

\subsection{Overall energy efficiency}

The overall energy efficiency is a critical indicator of battery performance, determining the economic potential of the technology. It is calculated by eq. (3-12) and plotted as a function of air utilization in Fig.11 for the three cases. For Case-1, the energy efficiency decreases with air utilization because of the increased demand for external heat as air utilization increases. For Case-2, the energy efficiency peaks at air utilization of $13 \%$, which is consistent with the heat balance shown in Fig.7. For air utilization other than 13\%, more energy demand from air pump and external heater would lower the efficiency. For Case-3, the energy efficiency increases gradually with air utilization without peaking within the range studied. The more heat generated under higher operating current density may shift the peak efficiency toward even higher air utilization. Overall, the system energy efficiency is above $70 \%$ for the three cases, indicating that IT-SOIARB is an efficient battery technology. 


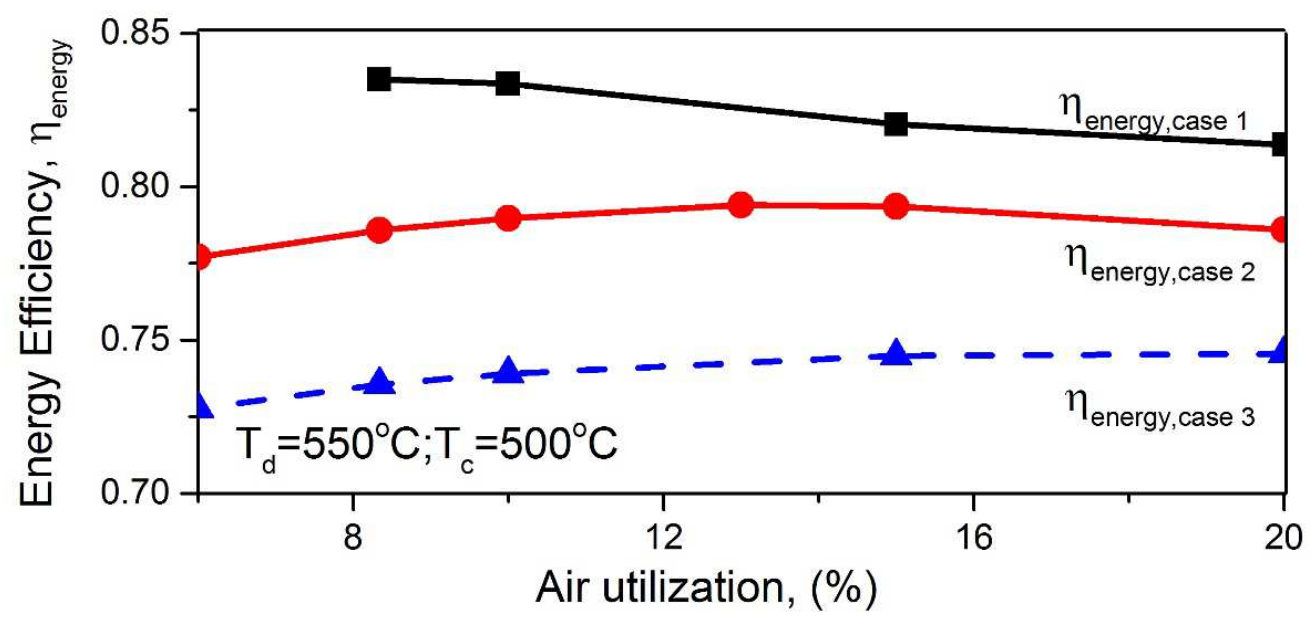

Fig. 11 Total energy efficiency $v s$ air utilization

\section{Conclusions}

For the IT-SOIARB system analyzed in this study the heat exchanger and thermal storage unit are used as a means of increasing the overall energy efficiency of the system. Air is employed as a working fluid to exchange, move and store heat involved in the battery components. The results show that lower air utilization is needed for low current density operation in order to reach a heat balance and achieve high energy efficiency. The critical air utilizations needed for Case- 1 and -2 are $8 \%$ and $13 \%$, respectively, above which external heat is needed. For Case-3, no external heat is needed for air utilization less than $20 \%$. The energy efficiency is generally flat with regard to air utilization, but is higher at lower current density. The energy efficiency is shown to be above $70 \%$, indicating that the IT-SOIARB is a promising battery technology. 


\section{Acknowledgements}

The information, data or work presented herein was funded in part by the Advanced Research

Projects Agency-Energy (ARPA-E), U.S. Department of Energy, under Award number DEAR0000492. The authors would also like to acknowledge the support from a grant (Project Number: PolyU 152127/14E) from Research Grant Council, University Grants Committee, Hong Kong SAR.

\section{Nomenclature}

$<$ xps:span class=deft $>A,\left(\mathrm{~m}^{2}\right)</ x p s:$ span $><x p s:$ span class=defd $>$ Cross area of ITSOIARB $</$ xps:span $>$

$<$ xps:span class $=$ deft $>\mathrm{C}_{\mathrm{p}},\left(\mathrm{J} \cdot \mathrm{kg}^{-1} \cdot \mathrm{K}^{-1}\right)</$ xps:span $><x p s$ :span class=defd $>$ Heat capacity $</ x p s:$ span $>$ $<$ xps:span class $=$ deft $>$ D,$\left(\mathrm{m}^{2} \cdot \mathrm{s}^{-1}\right)</$ xps:span $><x p s$ :span class=defd $>$ Diffusion coefficient $</ x p s:$ span $>$ $<x p s$ :span class=deft $>E,(\mathrm{kWh})</ x p s:$ span $><x p s:$ span class=defd $>$ Energy input or output $</ x p s: s p a n>$ $<$ xps:span class $=$ deft $>\mathrm{F},\left(\mathrm{C} \cdot \mathrm{mol}^{-1}\right)</$ xps:span $><$ xps:span class=defd $>$ Faraday's constant, $96485</$ xps:span>

$<$ xps:span class=deft $>\mathrm{F}_{\text {air }},\left(\mathrm{mol} \cdot \mathrm{s}^{-1}\right)</ x p s:$ span $><x p s$ :span class=defd $>$ Molar flow rate of air $</ x p s:$ span $>$

$<$ xps:span class=deft $>F_{O_{2}},\left(\mathrm{~mol} \cdot \mathrm{s}^{-1}\right)</$ xps:span $><$ xps:span class=defd $>$ Molar flow rate of $\mathrm{O}_{2}</$ xps:span $>$

$<$ xps:span class=deft $>F_{F e},\left(\mathrm{~mol} \cdot \mathrm{s}^{-1}\right)</ x p s:$ span $><x p s:$ span class=defd $>$ Molar flow rate of $\mathrm{Fe}</$ xps:span $>$

$<$ xps:span class=deft $>F_{\mathrm{Fe}_{3} \mathrm{O}_{4}},\left(\mathrm{~mol} \cdot \mathrm{s}^{-1}\right)</$ xps:span $><x p s:$ span class=defd $>$ Molar flow rate of $\mathrm{Fe}_{3} \mathrm{O}_{4}</ x p s:$ span $>$

$<$ xps:span class $=$ deft $>\mathrm{G},\left(\mathrm{J} \cdot \mathrm{mol}^{-1}\right)</$ xps:span $><$ xps:span class=defd $>$ Gibbs free energy $</ x p s:$ span $>$ $<x$ s:span class=deft $>\Delta$ Heat, $(\mathrm{kWh})</ x p s:$ span $><x p s:$ span class $=$ defd $>$ External heat flow provided to SOIARB at charge cycle $</ x p s:$ span $>$

$<x p s:$ span class=deft $>h_{\text {cycle }},(\mathrm{h})</ x p s:$ span $><x p s:$ span class=defd $>$ Cycle time in hour $</ x p s: s p a n>$ $<x p$ :span class $=$ deft $>\mathrm{J},\left(\mathrm{A} \mathrm{m}^{-2} \cdot \mathrm{s}^{-1}\right)</$ xps:span $><x p s:$ span class $=$ defd $>$ Current density $</ x p s:$ span $>$ $<x$ s:span class $=$ deft $>\mathrm{J}_{\text {ict }},\left(\mathrm{A} \mathrm{m}^{-2} \cdot \mathrm{s}^{-1}\right)</$ xps:span $><$ xps:span class $=$ defd $>$ Local charge transfer current density</xps:span>

$<$ xps:span class=deft $>\mathrm{M}_{\text {air }},\left(\mathrm{kg} \cdot \mathrm{mol}^{-1}\right)</$ xps:span $><x p s:$ span class=defd $>$ Molar weight $</ x p s:$ span $>$ 
$<x p s:$ span class=deft $>n,(\mathrm{~mol})</$ xps:span $><x p s:$ span class=defd $>$ Number of exchanged electrons $</$ xps:span $>$

$<x p s$ :span class=deft $>\mathrm{OCV},(\mathrm{V})</$ xps:span $><x p s:$ span class=defd $>$ Open circuit voltage $</ x p s:$ span $>$ $<x p s:$ span class=deft $>$ p $,(\mathrm{Pa})</ x p s:$ span $><x p s$ :span class=defd $>$ Pressure $</ x p s:$ span $>$ $<x p s:$ span class=deft $>\mathrm{P},(\mathrm{kW})</$ xps:span $><x p s:$ span class=defd $>$ Power $</ x p s: s p a n>$ $<x p s:$ span class $=$ deft $>$ PA $</$ xps:span $><x p s:$ span class=defd $>$ Power output/input $</$ xps:span $>$ $<x p s:$ span class $=$ deft $>Q,(W)</ x p s:$ span $><x p s:$ span class $=$ defd $>$ Heat $</ x p s:$ span $>$ $<x$ s:span class=deft $>Q C A</ x p s:$ span $><x p s:$ span class=defd $>$ Heat stream to/from the battery</xps:span>

$<x p s:$ span class $=$ deft $>\mathrm{R},\left(\mathrm{J} \cdot\left(\mathrm{mol}^{-1} \cdot \mathrm{K}^{-1}\right)\right)</$ xps:span $><x p s:$ span class $=$ defd $>$ Gas constant, $8.314</$ xps:span>

$<x p s:$ span class=deft $>\mathrm{R}_{\text {air }}</ x p s:$ span $><x p s:$ span class=defd $>$ Air utilization ratio $</ x p s:$ span $>$ $<$ xps:span class=deft $>$ S1 $</$ xps:span $><x p s$ :span class=defd $>$ Heat leakage of the battery $</ x p s:$ span $>$ $<x$ s:span class=deft $>$ S4 $</$ xps:span $><x p s:$ span class=defd $>$ Heat stored in TSU for discharge cycle</xps:span>

$<x p s:$ span class=deft $>$ S17 $</$ xps:span $><x p s:$ span class=defd $>$ Heat restored from TSU for charge cycle</xps:span>

$<x p s:$ span class=deft $>\mathrm{T},(\mathrm{K})</$ xps:span $><x p s:$ span class=defd $>$ Temperature $</ x p s:$ span $>$ $<x p s:$ span class=deft $>V,(V)</ x p s: s p a n><x p s:$ span class=defd $>$ Voltage $</ x p s: s p a n>$ $<x p s:$ span class $=$ deft $>V_{m},\left(\mathrm{~m}^{3} \cdot \mathrm{mol}^{-1}\right)</ x p s:$ span $><x p s:$ span class $=$ defd $>$ Molar volume of air</xps:span>

\section{Greek symbols}

$\begin{array}{ll}\sigma,\left(\mathrm{S} \cdot \mathrm{m}^{-1}\right) & \text { Conductivity } \\ \varepsilon & \text { Porosity of electrodes, } \\ \tau & \text { Tortuosity of electrodes } \\ \eta,(\mathrm{V}) & \text { Overpotential } \\ \eta_{\text {eled }} \eta_{\text {energy }} & \text { Electric/Energy efficiency } \\ \delta,(\mu \mathrm{m}) & \text { Thickness }\end{array}$

$\begin{array}{ll}\text { Subscripts } & \\ \text { act } & \text { Activation overpotential loss } \\ \text { an } & \text { Anode } \\ \text { cat } & \text { Cathode } \\ \text { con } & \text { Concentration overpotential loss } \\ \text { c } & \text { Charge cycle } \\ \text { d } & \text { Discharge cycle } \\ \text { e } & \text { Electrode } \\ \text { eff } & \text { Effective } \\ \text { ele } & \text { Electrolyte } \\ \text { i,m,n } & \text { Species } \\ \text { L } & \text { Limiting } \\ \text { o } & \text { Oxygen electrode } \\ \text { ohm } & \text { Ohmic loss } \\ \text { h } & \text { Hydrogen electrode }\end{array}$




\section{Superscripts}

Ideal

\section{Meaning of Symbols}

\begin{tabular}{ll} 
IT-SOIARB & Intermediate-temperature Solid Oxide Iron Air Redox Battery \\
RSOFC & Reversible Solid Oxide Fuel Cell \\
RCU & Redox Cycle Unit \\
SOIARB & Solid Oxide Iron-Air Redox Battery \\
SOEC & Solid Oxide Electrolysis Cell \\
TSU & Thermal Storage Unit \\
\hline
\end{tabular}

\section{APPENDIX}

A 5kW/60kWh IT-SOIARB system intended for residential solar panel/battery applications was modeled by using ASPEN Plus. The simulation flow diagram for the system shown in Fig.1 is illustrated in Fig.A1, which contains all the components and functionalities specified in the ITSOIARB system. In the following, a detailed description of Fig.A1 is provided. Terms in italics represent the actual ASPEN Plus terminology. 
(a) Discharge

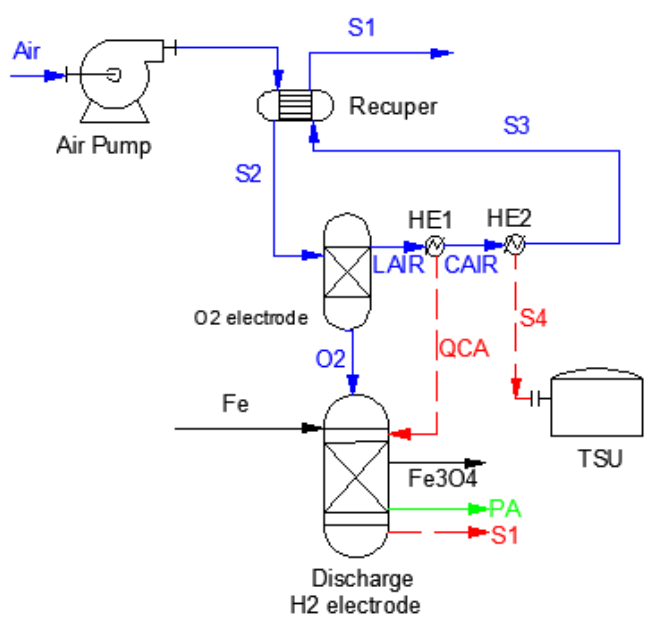

(b) Charge

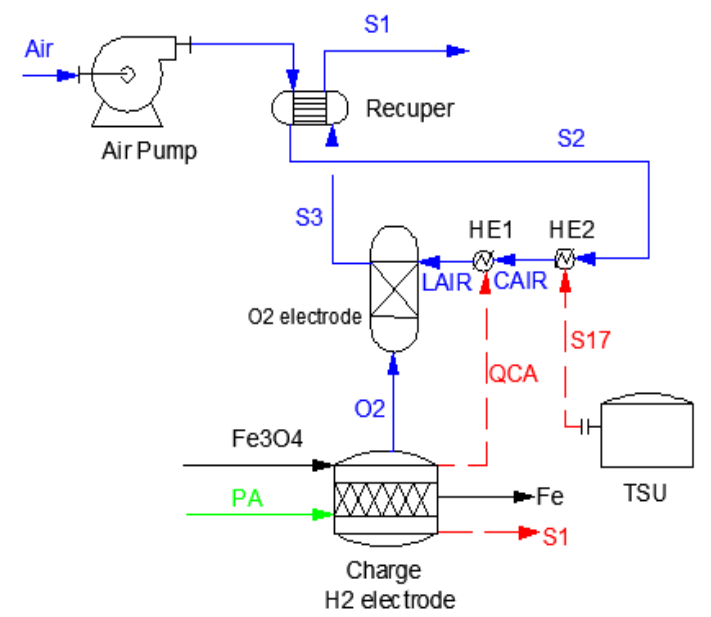

Fig. A1 An IT-SOIARB system represented by ASPEN Plus simulation flow diagrams: (a) Discharge cycle; (b) Charge cycle. (Blue solid line: air stream; black solid line: $\mathrm{Fe} / \mathrm{Fe}_{3} \mathrm{O}_{4}$ stream; green solid line: power input/output; red dashed line: heat stream.)

\section{A1. The heat exchanger for preheating air}

The inlet cold air (stream "AIR") shown in Fig.A1 for the IT-SOIARB stack under operation is first preheated by the hot exhaust air exiting from the TSU (stream "S3"). The heat exchange process is modeled in ASPEN Plus by a rigorous heat exchanger module Heatx (labeled as "Recuper"). Utilization of exhaust heat to raise the temperature of the inlet air is expected to improve the overall system efficiency. The temperature of the exhaust air stream "S1", heat stored in TSU, and operating current densities can be optimized to ensure sufficient heat supply for the charge cycle.

\section{A2. The IT-SOIARB in the discharge mode}

Since there is no built-in module for IT-SOIARB in ASPEN Plus, we used a separator module Sep (labelled as "O2 electrode") and an equilibrium reactor module Rgibbs (labeled as 
"Discharge H2 electrode") to simulate the battery behavior in conjunction with a heat stream (QCA) from the "HE1" - a temperature exchanger module Heater in ASPEN Plus, to the "Discharge H2 electrode" to maintain the same temperature for the two electrodes. The RCU is included in $\mathrm{H}_{2}$ electrode.

\section{A2.1. Oxygen supply}

The inlet cold air (stream "AIR") is heat-exchanged with the hot exhaust air (stream "S3"), and then enters the $\mathrm{O}_{2}$ electrode to provide oxygen for the electrochemical reaction. The latter is modeled by a separator module Sep (labelled as "O2 electrode") and a temperature exchanger module Heater (labelled as "HE1"). A fraction of oxygen (determined by the air utilization) from the inlet cold air is separated in the "O2-electrode" and enters the "Discharge $\mathrm{H} 2$ electrode" to oxidize Fe. An ASPEN Plus Calculator was used to calculate the molar flow rate of stream "O2"

from the feed $\mathrm{Fe}$ molar flow rate based on mass balance $F_{\mathrm{O}_{2}}=\frac{2}{3} F_{\mathrm{Fe}}$. The heat absorbed by the air stream exiting the battery in the discharging mode is represented by a heat stream (labelled as "QCA") from the "HE1" to the "Discharge O2 electrode". The heat QCA is quantified by equalizing the temperatures of the exhaust air stream (labeled as "CAIR") and the $\mathrm{H}_{2}$ electrode outlet (labeled as "FE3O4").

\section{A2.2 Electrochemical reaction at the $\mathrm{H}_{2}$ electrode}

To simulate the electrochemical reactions inside the IT-SOIARB, an equilibrium reactor module Rgibbs (labelled as "Discharge H2 electrode") was used. The overall reaction, shown in eq.(3-4), is considered to be in equilibrium at a given temperature, viz. $550^{\circ} \mathrm{C}$, for this study. Material stream "O2" $\left(\mathrm{O}_{2}\right.$ from $\mathrm{O}_{2}$-electrode) and "FE" (iron in the chemical bed) are supplied to the 
reactor to produce material stream "FE3O4" (iron oxide in the chemical bed), stream "PA", "S1" and "QCA"; the stream "PA" represents power output of the discharge cycle, $\mathrm{P}_{\mathrm{d}}$; "S1" is heat loss of the reactor, $\mathrm{P}_{\text {loss }}$; the stream "QCA" is the heat liberated by the IT-SOIARB to air stream.

\section{A3 The IT-SOIARB in the charge mode}

Because the backward reaction of eq.(3-4) occurring during the charge cycle is not spontaneous and "Fe3O4" is the only chemical supply, a different reactor type is selected for the charging unit, Rstoic (labeled as "Charge H2 electrode"), to simulate the charging reaction. This module is more appropriate when the reaction stoichiometry and conversion are known, which is the case for the charging reaction.

The product $\mathrm{O}_{2}$ separated from Fe enters "O2 electrode" and mixed with hot air "CAIR". The heat transferred from $\mathrm{O}_{2}$-electrode to $\mathrm{H}_{2}$-electrode is represented by heat stream "QCA", which connects "Charge H2 electrode" and "HE1". Because our goal is to reuse the heat generated during the discharge cycle for the charge cycle, there must exist a temperature gradient in the battery between cycles in order to transfer heat. We assume that the operating temperature of charge cycle is at $500^{\circ} \mathrm{C}$, whereas it is $550^{\circ} \mathrm{C}$ for the discharge cycle.

\section{A4 The Thermal Storage Unit (TSU)}

Due to the opposite heat flow between the discharge and charge cycles, a thermal storage unit (TSU) is included in the system to assist in reusing the heat generated during the discharge cycle for the charge cycle. The heat stored or reused by air is represented, respectively, by heat stream "S4" for the discharge cycle or "S17" for the charge cycle, which connects "HE2", a second heat exchanger, to "TSU". To ensure an efficient heat-transfer, we assume that the operating temperature of the TSU is at $525^{\circ} \mathrm{C}$. 
During the discharge cycle, the hot air "CAIR" from the battery with a temperature of $550^{\circ} \mathrm{C}$ passes through "HE2" to store part of the heat (S4) in "TSU" and exits with a temperature of $525^{\circ} \mathrm{C}$. During the charge cycle, the preheated air "S2" enters "HE2", which extracts all the heat stored in S17 of "TSU". The hot air "CAIR" then delivers some heat to the battery by Heat Stream "QCA" that connects "HE1" and "Charge H2 electrode". The heat stored or reused by S4 of the discharge cycle or S17 of the charge cycle can be calculated by:

$$
Q_{S 4 / S 17}=C_{p} \times M_{\text {air }} \times F_{\text {air }} \times\left(T_{\text {SOIARB }}-T_{T S U}\right) \times h_{\text {cycle }}
$$

where, $\mathrm{M}_{\mathrm{air}}$ and $\mathrm{F}_{\text {air }}$ are the molar weight and molar flow rate of air; $\mathrm{C}_{\mathrm{p}}$ is the hear capacity of air; $\mathrm{T}_{\text {SOIARB }}$ and $\mathrm{T}_{\mathrm{TSU}}$ are the operating temperatures of the SOIARB and TSU, respectively; $h_{c y c l e}$ is cycle time in hour.

\section{References}

1. A. Hazza, D. Pletcher and R. Wills, Phys Chem Chem Phys, 6, 1773 (2004).

2. J. F. Manwell and J. G. Mcgowan, Sol Energy, 50, 399 (1993).

3. J. Sabatier, M. Aoun, A. Oustaloup, G. Gregoire, F. Ragot and P. Roy, Signal Process, 86, 2645 (2006).

4. $\quad$ M. B. J. G. Freitas and S. F. Rosalem, J Power Sources, 139, 366 (2005).

5. $\quad$ R. Sebastian and R. P. Alzola, Renew Energ, 35, 952 (2010).

6. T. Sakai, I. Uehara and H. Ishikawa, J Alloy Compd, 293, 762 (1999).

7. C. Rongeat, M. H. Grosjean, S. Ruggeri, A. Dehmas, S. Bourlot, S. Marcotte and L. Roue, J Power Sources, 158, 747 (2006).

8. $\quad$ M. Tsukahara, K. Takahashi, A. Isomura and T. Sakai, J Alloy Compd, 287, 215 (1999).

9. L. J. Gao, S. Y. Liu and R. A. Dougal, Ieee Transactions on Components and Packaging Technologies, 25, 495 (2002).

10. B. Scrosati, Electrochim Acta, 45, 2461 (2000).

11. J. Shim, R. Kostecki, T. Richardson, X. Song and K. A. Striebel, J Power Sources, 112, 222 (2002).

12. M. Rychcik and M. Skyllas-Kazacos, J Power Sources, 22, 59 (1988).

13. M. Skyllas-Kazacos, J Power Sources, 124, 299 (2003). 
14. W. Wang, Q. T. Luo, B. Li, X. L. Wei, L. Y. Li and Z. G. Yang, Adv Funct Mater, 23, 970 (2013).

15. X. C. Lu, B. W. Kirby, W. Xu, G. S. Li, J. Y. Kim, J. P. Lemmon, V. L. Sprenkle and Z. G. Yang, Energ Environ Sci, 6, 299 (2013).

16. C. W. Park, H. S. Ryu, K. W. Kim, J. H. Ahn, J. Y. Lee and H. J. Ahn, J Power Sources, 165, 450 (2007).

17. J. L. Wang, J. Yang, Y. Nuli and R. Holze, Electrochem Commun, 9, 31 (2007).

18. N. S. Xu, X. Li, X. Zhao, J. B. Goodenough and K. Huang, Energ Environ Sci, 4, 4942 (2011).

19. N. H. Menzler, A. Hospach, L. Niewolak, M. Bram, O. Tokariev, C. Berger, P. Orzessek, W. J. Quadakkers, Q. Fang and H. P. Buchkremer, ECS Transactions, 57, 255 (2013).

20. A. M. Pour, A. Dhir and R. Steinberger-Wilckens, ECS Transactions, 57, 243 (2013).

21. A. Leonide, W. Drenckhahn, H. Greiner and H. Landes, J Electrochem Soc, 161, A1297 (2014).

22. H. T. Wang, J. T. Chen, C. H. Luo and R. Qiao, Solid State Ionics, 263, 71 (2014).

23. X. Zhao, Y. H. Gong, X. Li, N. S. Xu and K. Huang, J Electrochem Soc, 160, A1241 (2013).

24. X. Zhao, Y. H. Gong, X. Li, N. S. Xu and K. Huang, J Electrochem Soc, 160, A1716 (2013).

25. X. Zhao, X. Li, Y. Gong and K. Huang, Chemical Communications, 623 (2014).

26. A. Inoishi, Y. W. Ju, S. Ida and T. Ishihara, J Power Sources, 229, 12 (2013).

27. A. Inoishi, Y. Okamoto, Y. W. Ju, S. Ida and T. Ishihara, Rsc Adv, 3, 8820 (2013).

28. A. Inoishi, T. Sakai, Y. W. Ju, S. Ida and T. Ishihara, J Power Sources, 262, 310 (2014).

29. A. Inoishi, T. Sakai, Y. W. Ju, S. Ida and T. Ishihara, J Mater Chem A, 1, 15212 (2013).

30. X. Zhao, Y. H. Gong, X. Li, N. S. Xu and K. Huang, J Mater Chem A, 1, 14858 (2013).

31. X. Zhao, X. Li, Y. H. Gong, N. S. Xu, K. Romito and K. Huang, Chemical Communications, 49, 5357 (2013).

32. X. Zhao, N. S. Xu, X. Li, Y. H. Gong and K. Huang, Rsc Adv, 2, 10163 (2012).

33. A. Inoishi, S. Ida, S. Uratani, T. Okano and T. Ishihara, Rsc Adv, 3, 3024 (2013).

34. A. Inoishi, Y. W. Ju, S. Ida and T. Ishihara, Chemical Communications, 49, 4691 (2013).

35. M. Guo, X. Zhao, R. E. White and K. Huang, J Electrochem Soc, 160, A2085 (2013).

36. H. Ohmori, S. Uratani and H. Iwai, J Power Sources, 208, 383 (2012).

37. X. Jin, A. M. Uddin, X. Zhao, R. White and K. Huang, J Electrochem Soc, Accepted (2015).

38. X. Jin, X. Zhao and K. Huang, J Power Sources, 280, 195 (2015).

39. X. Jin, A. M. Uddin, X. Zhao, R. White and K. Huang, J Electrochem Soc, 162, A1476 (2015).

40. X. Jin, X. Zhao and K. Huang, in 2014 MRS Fall Meeting (2015).

41. X. Jin, X. Zhao, R. E. White and K. Huang, J Electrochem Soc, Accepted (2015).

42. Aspen Plus V8.4, in, Aspen Tech Ltd, Cambridge MA, USA.

43. S. Campanari, J Power Sources, 92, 26 (2001).

44. W. Zhang, E. Croiset, P. L. Douglas, M. W. Fowler and E. Entchev, Energ Convers Manage, 46, 181 (2005).

45. P. Lisbona, A. Corradetti, R. Bove and P. Lunghi, Electrochim Acta, 53, 1920 (2007).

46. X. Zhao, A New Class of Solid Oxide Metal-Air Redox Batteries for Advanced Stationary Energy Storage, in Mechanical Engineering, University of South Carolina (2013). 
47. X. Zhao, X. Li, Y. H. Gong, N. S. Xu and K. Huang, Rsc Adv, 4, 22621 (2014).

Table 1 Summary of parameters used in the FORTRAN model

\begin{tabular}{lc}
\hline Parameters & Values \\
Atmospheric pressure, $\mathrm{P}_{0}$ & $1[\mathrm{~atm}]$ \\
Cross-sectional area of SOIARB, A & $35\left[\mathrm{~m}^{2}\right]$ \\
Exchange current density, Anode/Cathode, $\mathrm{J}_{0} *$ & $400 / 400\left[\mathrm{~A} / \mathrm{m}^{2}\right]$ \\
Effective diffusion coefficient $\mathrm{H}_{2}-\mathrm{H}_{2} \mathrm{O}, \mathrm{D}_{\text {eff,h2h2o }}$ & $5.4 \times 10^{-4}\left[\mathrm{~m}^{2} / \mathrm{s}\right]$ \\
Effective diffusion coefficient $\mathrm{O}_{2}-\mathrm{N}_{2}, \mathrm{D}_{\text {eff,o2n } 2}$ & $1.21 \times 10^{-4}\left[\mathrm{~m}^{2} / \mathrm{s}\right]$ \\
Heat loss of SOIARB stack, $\mathrm{Q}_{\text {loss }}$ & $2 \%$ \\
Ionic conductivity, $\sigma_{\mathrm{i}, \text { el }}{ }^{*}$ & $0.4[\mathrm{~S} / \mathrm{m}]$ \\
Molar fraction of $\mathrm{H}_{2}, \mathrm{X}_{\text {ref,H2 }}$ & 0.79 \\
Molar fraction of $\mathrm{O}_{2}, \mathrm{x}_{\text {ref,O2 }}$ & 0.21 \\
Porosity of electrodes, $\varepsilon$ & 0.3 \\
Tortuosity of electrodes, $\tau$ & 4 \\
Temperature of Discharge/Charge cycle, $\mathrm{T}_{0}$ & $550 / 500\left[{ }^{\circ} \mathrm{C}\right]$ \\
Thickness of electrolyte, $\delta_{\text {ele }}$ & $180[\mu \mathrm{m}]$ \\
Thickness of $\mathrm{O}_{2} / \mathrm{H}_{2}$ electrode, $\delta_{e}$ & $50 / 30[\mu \mathrm{m}]$ \\
\hline
\end{tabular}

